\title{
ANALISIS PENGARUH SUKU BUNGA KREDIT DAN KRISIS EKONOMI TERHADAP PENANAMAN MODAL DALAM NEGERI DI INDONESIA TAHUN 1990-2010
}

\author{
Oleh: \\ Salman Alfarisi \\ Staf PT. Kuda Inti Samudera \\ E-mail/No. Hp : ryrz_its_me@yahoo.com/ -
}

\begin{abstract}
Abstact
This study aims to determine the development of domestic direct investment (DDI) with lending rates level and to determine the effect of lending rates and economic crisis on domestic direct investment (DDI) in Indonesia in 1990-2010. Based on the result of regression analysis found that the coefficient value of determination $\left(R^{2}\right)$ is 0.499 . It means the ability of the independent variables consist of lending rates level and economic crisis which is able to explain $49 \%$ of the dependent variable that is domestic direct investment (DDI). From the test results obtained the level of lending rates have a significant influence on domestic direct investment (DDI) this is proved by $t$ count $>t$ table is amounted to $-4.235>$ 2.101. On the other hand, the economic crisis has the value t count is 2.432, therefore, the economic crisis also significantly influence the domestic direct investment (DDI). Obtained from the F test that both of lending rates level and economic crisis significantly influence on domestic direct investment (DDI). This is proved by the value of $F$ count (8.972) > F table (3.55).
\end{abstract}

Keywords: lending rates, economic crisis, and domestic direct investment

\begin{abstract}
Abstrak
Penelitian ini bertujuan untuk mengetahui perkembangan penanaman modal dalam negeri (PMDN) dengan tingkat suku bunga kredit dan untuk mengetahui pengaruh tingkat suku bunga kredit dan krisis ekonomi terhadap penanaman modal dalam negeri (PMDN) di Indonesia pada tahun 1990-2010.Berdasarkan hasil analisis regresi didapat bahwa nilai koefisien determinasi $\left(R^{2}\right)$ sebesar 0.499. Hal ini berarti kemampuan variabel bebas yang terdiri dari tingkat suku bunga kredit dan krisis ekonomi dapat menjelaskan $49 \%$ vaiabel terikat yaitu penanaman modal dalam negeri (PMDN). Dari hasil uji t didapat bahwa tingkat suku bunga kredit mempunyai pengaruh signifikan terhadap penanaman modal dalam negeri (PMDN) hal ini dibuktikan dengan thitung > t tabel yaitu sebesar 4.235>2.101. Begitu juga dengan krisis ekonomi yang mempunyai nilai $t$ hitung sebesar 2.432, jadi krisis ekonomi juga berpengaruh signifikan terhadap penanaman modal dalam negeri (PMDN). Dari uji F didapat bahwa tingkat suku bunga kredit dan krisis ekonomi secara bersama-sama berpengaruh signifikan terhadap penanaman modal dalam negeri (PMDN). Hal ini dibuktikan dengan nilai F hitung (8.972) > F tabel (3.55).
\end{abstract}

Kata Kunci: suku bunga kredit, krisis ekonomi, dan penanaman modal dalam negeri 


\section{PENDAHULUAN}

Indonesia termasuk salah satu negara yang sedang berkembang yang dalam proses globalnya membutuhkan sarana dan prasarana guna menunjang proses pembangunan yang seutuhnya. Salah satu sektor vital didalam suatu pembangunan negara adalah sektor ekonomi, karena pembangunan tidak berjalan dengan semestinya apabila sektor ekonominya tidak memadai. Untuk itu salah satu wujud nyata dari sektor ekonomi untuk merealisasikan pembangunan yang seutuhnya adalah dengan melakukan investasi baik dalam negeri (PMDN) maupun investasi luar negeri (PMA). Investasi dalam negeri dilakukan oleh pemerintah nasional maupun swasta di Indonesia dengan tujuan untuk menciptakan suatu produksi, sedangkan investasi asing (PMA) adalah modal yang di tanamkan oleh pihak asing untuk memulai usaha di negara lain.

Investasi merupakan unsur utama dalam pembangunan ekonomi suatu negara untuk mencapai tingkat pertumbuhan ekonomi yang di kehendaki, maka diperlukan sejumlah Investasi tertentu yang dibiayai dengan tabungan nasional. Di negaranegara yang sedang berkembang seperti halnya Indonesia tidak mempunyai sumber dana yang cukup guna membiayai pembangunan negerinya. Indonesia membutuhkan dana yang cukup besar untuk melaksanakan pembangunan nasional. Kebutuhan dana yang besar tersebut terjadi karena adanya upaya untuk mengejar ketertinggalan pembangunan dari negara-negara maju, baik di kawasan regional maupun kawasan global. Indonesia masih belum mampu menyediakan dana pembangunan tersebut. Terbatasnya akumulasi berupa kapital tabungan di dalam negeri. Selain itu dikarenakan oleh rendahnya produktivitas, dan tingginya konsumsi. Sejalan dengan sasaran pembangunan bahwa sasaran pembangunan di titik beratkan di bidang ekonomi yaitu penataan swastanisasi nasional yang mengarah pada penguatan, peningkatan, perluasan dan penyebaran sektor swasta keseluruh wilayah Indonesia, maka investasi ke sektor swasta adalah pendukung pembangunan nasional untuk mencapai tujuantujuan pembangunan nasional. 
Kebijakan pembangunan Indonesia mencakup pengembangan iklim usaha dan investasi, peningkatan swasta nasional pengembangan usaha kecil dan menengah.

Penggairahan iklim investasi di Indonesia khususnya Penanaman Modal Dalam Negeri (PMDN) dimulai dengan diundangkannya Undang-Undang No. 6/Tahun 1968. Pemberlakukan undang-undang ini menyusul tampilnya rejim orde baru memegang tumpuk pemerintahan. Kemudian undang-undang tadi dilengkapi dan disempurnakan menjadi UU No. 12/Tahun 1970. Semenjak diberlakukan UndangUndang No. 6/Tahun 1968 jo. No. 12/Tahun 1970 tentang Penanaman Modal Dalam Negeri (PMDN), pertumbuhan investasi cenderung meningkat dari waktu ke waktu. Walaupun demikian, pada tahuntahun tertentu sempat juga terjadi penurunan.

Kecenderungan peningkatan bukan hanya berlangsung pada investasi oleh kalangan masyarakat atau sektor swasta, namun juga penanaman modal oleh pemerintah.

Tantangan Indonesia dalam memperbaiki iklim investasi tercermin dari rendahnya peringkat yang dimiliki dihampir sebagian besar index internasional yang telah diakui di dunia seperti The World Bank's Doing Business (129/181) dan Transparency International's Corruption Perception Index (126/180). Namun berdasarkan World Economic Forum's Global Competitiveness Index (55/134) dan Global Peace Index (68/140), peringkat Indonesia sebenarnya sedikit lebih baik. Walaupun terdapat beberapa masalah dengan index ini, namun index ini tetap mampu menunjukkan kinerja Indonesia terhadap Negara lain. Dan yang terpenting adalah adanya peningkatan yang bersifat relative bukan peningkatan yang bersifat absolute bila ingin bersaing dalam menarik investasi. Selain dari peringkat tersebut tantangan lain yang di alami oleh Indonesia dalam mencerahkan iklim investasinya adalah tantangan secara internal maupun eksternal. Dari dalam negeri, tantangan itu antara lain masih belum memadainya sarana dan prasarana perekonomian yang berupa barang-barang publik. Sementara keuangan pemerintah justru harus dikelola lebih efisien, 
kalangan swasta biasanya enggan atau tidak tertarik untuk menanam modal bagi penyediaan barang publik. Tantangan lain adalah rendahnya produktifitas pekerja dan efisiensi produksi, kelangkaan tenaga kerja terampil, serta kurang teraminnya kepastian hukum bagi investor. Sedangkan faktor eksternalnya adalah berupa persaingan iklim investasi dengan beberapa negara di kawasan Asia-Pasifik, terutama China.
Investasi bukanlah suatu jaminan terciptanya pembangunan ekonomi yang baik. Satu hal yang penting yaitu bukan jumlah investasi yang begitu besar atau jumlah proyek yang ada melainkan adalah bagaimana cara untuk memanfaatkan investasi tersebut seefisien mungkin sehingga menciptakan produktivitas dalam investasi tersebut.

\section{Gambar 1. Penanaman Modal Dalam Negeri di Indonesia Tahun 1990-2010 (Miliar Rp)}

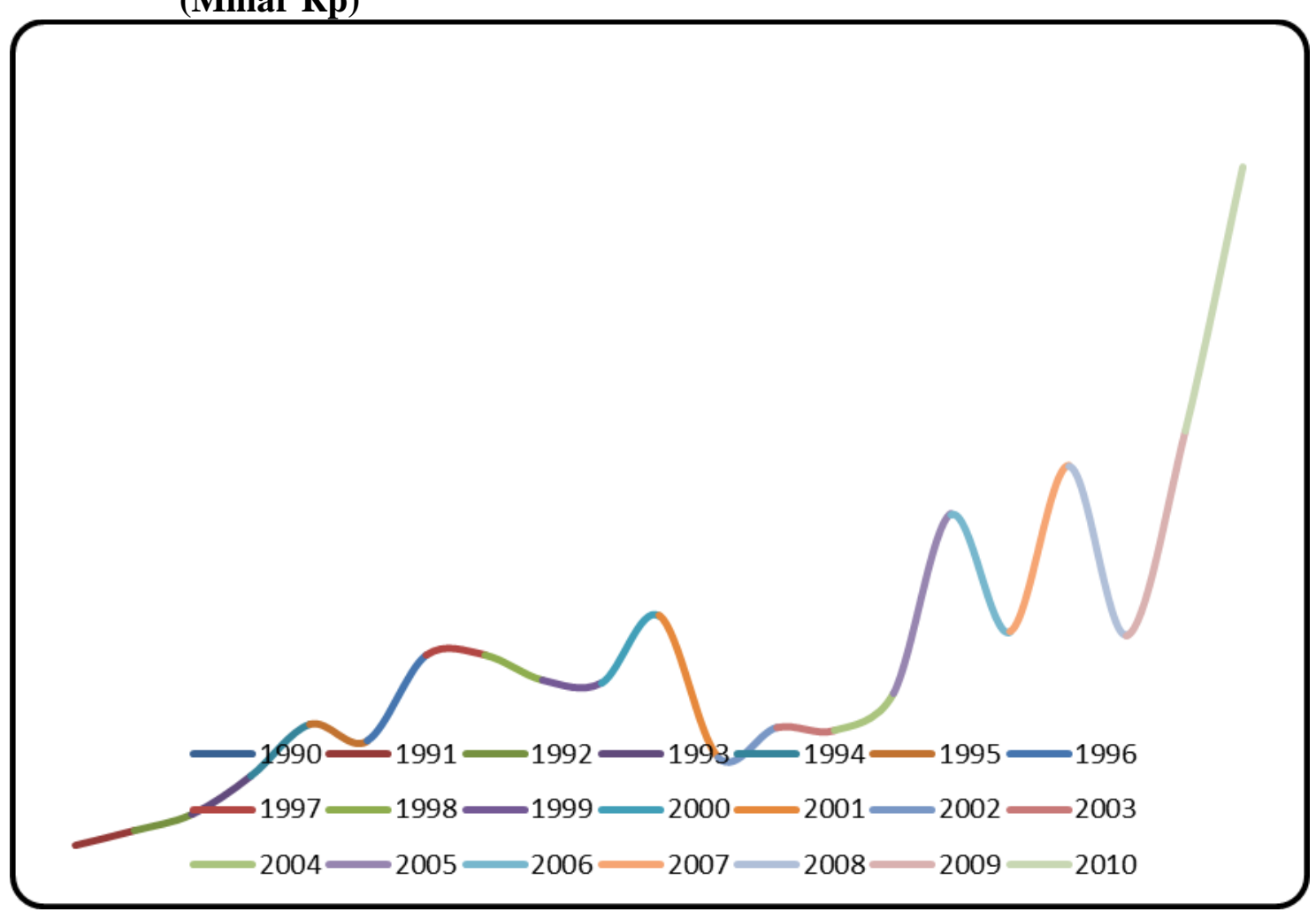

Sumber: www.bkpm.go.id (diolah)

Sumber daya alam yang ada dimiliki oleh Indonesia sangat banyak juga harus dapat dimanfaatkan secara sehingga diperlukan aktivitas optimal. Sumber daya alam yang penanaman modal baik PMA dan 
PMDN. Disetiap wilayah Indonesia tersedia berbagai bahan mentah dari berbagai hasil pertanian, perkebunan, perikanan dan peternakan yang dapat digunakan oleh sektor industri. Disamping itu terdapat pula potensi yang besar dari sektor pertambangan, perindustrian dan sebagainya. Semua faktor-faktor ini memerlukan investasi yang relatif besar untuk mengelolanya.

Apabila sumber daya tersebut dapat dikelola dengan baik maka akan berakibat pada kelangsungan proses pembangunan ekonomi. Pembangunan ekonomi melibatkan kegiatan kegiatan produksi barang dan jasa di semua sektor-sektor ekonomi. Terciptanya kegiatankegiatan produksi dapat mendorong terciptanya kesempatan kerja dan peningkatan pendapatan masyarakat, yang selanjutnya meningkatkan permintaan di pasar. Terjadinya perkembangan pasar menunjukkan bahwa volume kegiatan produksi juga berkembang, kesempatan kerja dan pendapatan di dalam negeri akan meningkat sehingga dapat menciptakan pertumbuhan ekonomi.

Laju investasi khusunya Penanaman Modal Dalam Negeri
(PMDN) cenderung berfluktuasi. Pada tahun tertentu mengalami penurunan yang sangat tajam dan pada tahun tertentu pula mengalami kenaikan yang sangat drastis. Hal ini dapat dilihat dari gambar Penanaman Modal Dalam Negeri (PMDN) di Indonesia. Joseph Schumpeter adalah seorang tokoh pemikir ekonomi asal Amerika berpendapat bahwa, investasi yang lazim disebut juga dengan istilah penanaman modal atau pembentukan modal merupakan komponen kedua yang menentukan tingkat pengeluaran agregat. Dengan demikian istilah investasi dapat diartikan sebagai pengeluaran atau perbelanjaan penanam-penanaman modal atau perusahaan untuk membeli barang-barang modal dan perlengkapan-perlengkapan untuk menambah kemampuan memproduksi barang-barang dan jasa-jasa yang tersedia dalam perekonomian. Pertambahan jumlah barang modal ini memungkinkan perekonomian tersebut menghasikan lebih banyak barang dan jasa di masa yang akan datang. Adakalanya penanaman modal dilakukan untuk menggantikan barang-barang modal yang lama yang telah haus dan perlu didepresiasikan. 


\section{METODE PENELITIAN}

Variabel dependen dalam penelitian ini yaitu Penanaman Modal Dalam Negeri (PMDN). PMDN adalah investasi yang dilakukan oleh pemerintah nasional maupun swasta di Indonesia dengan tujuan untuk menciptakan suatu produksi. Data yang digunakan merupakan nilai realisasi PMDN per tahun di Indonesia dari periode 1990-2010 yang diperoleh dari Badan Koordinasi Penanaman Modal (BKPM) dan dinyatakan dalam milyar rupiah.

Sedangkan variabel independen dalam penelitian ini yaitu tingkat suku bunga kredit dan variabel dummy. Suku bunga kredit adalah suatu biaya pinjaman. Data yang digunakan adalah data per tahun dari periode 1990-2010 yang diperoleh dari Bank Indonesia dan dinyatakan dalam persen.

Variabel dummy yang digunakan dalam penelitian ini adalah krisis ekonomi. Indonesia mengalami krisis ekonomi pada tahun 1998, dimana tahun yang terkena dampak krisis ekonomi adalah tahun 19982002.
Untuk menganalisis data yang diperoleh, menggunakan model dasar dari persamaan estimasi OLS (Ordinary Least Square). Persamaan estimasi OLS yang di gunakan adalah $\mathrm{Y}=\beta_{0}+\beta_{1} \mathrm{X}_{1}+\beta_{2} \mathrm{DmX}_{2}+\mathrm{e} \ldots \ldots$

Dimana, Y : Investasi (Mrp per tahun); $\mathrm{X}_{1}$ : Suku Bunga (\% per tahun); Dm: Variabel Dummy (Krisis Ekonomi) yaitu angka $0=$ Tidak Terjadi Krisis Ekonomi; angka $1=$ Terjadi Krisis Ekonomi.

Dikarenakan adanya parameter yang berbeda dalam variabel tersebut, maka persamaan diatas akan dirubah menjadi model log-log atau double log. Jadi persamaan di atas menjadi : $L Y=\beta_{0}+\beta_{1} X_{1}+\beta_{2} D m X_{2}+e \ldots \ldots$ (2)

Adapun uji statistik yang dilakukan dalam penelitian ini yaitu Uji Koefisien Determinasi $\left(\mathrm{R}^{2}\right)$, Uji t, dan Uji F.

\section{PEMBAHASAN}

Untuk menganalisis data antara tingkat suku bunga kredit dan krisis ekonomi terhadap Penanaman Modal Dalam Negeri (PMDN) di Indonesia menggunkan metode OLS (Ordinary 
Least Square) dengan standart kepercayaan $\alpha=5 \%$. Hasil dari analisis data tersebut dapat dilihat pada tabel 2 .

Dari hasil analisis data didapatkan R-Squared sebesar 0.499 atau $49.9 \%$ dan F-Statistik sebesar 8.972 dengan F-Signifikan sebesar 0.002. Berdasarkan tabel 2 diperoleh model persamaan regresi linier berganda sebagai berikut : $\mathrm{Y}=5.650$ $-0.094 X_{1}+0.371 X_{2}+$ e.

$\beta_{0}$ sebesar 5.650, hal ini berarti bahwa variabel PMDN sebesar 5.650 pada saat variabel suku bunga kredit dan krisis ekonomi sebesar 0 / konstan; $\beta_{1}$ sebesar -0.094 , Hal ini berarti koefisien regresi variabel suku bunga kredit (X1) sebesar -0.094. Maka ada hubungan negative antara variabel suku bunga kredit terhadap PMDN sebesar 0.094. Jadi apabila suku bunga kredit naik $1 \%$ maka PMDN turun sebesar $9.4 \%$ dan sebaliknya jika suku bunga turun $1 \%$ maka PMDN naik sebesar $9.4 \%$. $\beta_{2}$ sebesar 0.371. Hal ini berarti koefisien regresi variabel krisis ekonomi (X2) sebesar 0.371. Maka krisis ekonomi mempunyai pengaruh terhadap penanaman modal dalam negeri sebesar 0.371 .

Agar mengetahui pengaruh antara varabel independen terhadap variabel dependen maka dilakukan Uji t dengan kriteria pengujian yaitu Jika $\mathrm{t}$ tabel $>\mathrm{t}$ hitung, maka $\mathrm{Ha}$ ditolak dan Ho diterima, ini berarti variabel independen secara individual tidak berpengaruh secara signifikan terhadap variabel dependen. Jika $\mathrm{t}$ tabel $<\mathrm{t}$ hitung, Ha diterima dan Ho ditolak, ini berarti variabel independen secara individu berpengaruh secara signifikan terhadap variabel dependen. Hasil dari analisis data tersebut dapat dilihat pada tabel 3 .

Tabel 2. Hasil Regresi

\begin{tabular}{lrrrl}
\hline \multicolumn{1}{c}{ Variabel } & Koefisien & t-Statistik & Signifikan & Keterangan \\
\hline C & 5.650 & 15.816 & 0.000 & Signifikan \\
SBK & -0.094 & -4.235 & 0.000 & Signifikan \\
Dkrisis & 0.371 & 2.432 & 0.026 & Signifikan \\
\hline
\end{tabular}

Sumber : Data diolah

Tabel 3. Hasil Uji t

\begin{tabular}{lrrrc}
\hline \multicolumn{1}{c}{ Variabel } & Koefisien & t-Statistik & t-tabel & Signifikan \\
\hline C & 5.650 & 15.816 & 2.101 & 0.000 \\
SBK & -0.094 & -4.235 & 2.101 & 0.000 \\
Dkrisis & 0.371 & 2.432 & 2.101 & 0.026 \\
\hline
\end{tabular}


Variabel Suku Bunga Kredit $\left(X_{1}\right)$ memiliki nilai t hitung sebesar -4.235 dan nilai signifikan sebesar 0.000 . Hal ini berarti nilai t hitung (4.235) > t tabel (2.101) maka $\mathrm{Ha}$ diterima dan Ho ditolak, dengan demikian bahwa variabel suku bunga kredit (X1) berpengaruh signifikan terhadap PMDN.

Untuk variabel Krisis Ekonomi (X2) memiliki nilai t hitung sebesar 2.432 dan nilai signifikan sebesar 0.026. Hal ini berarti nilai t hitung $(2.432)>\mathrm{t}$ tabel (2.101) maka $\mathrm{Ha}$ diterima dan Ho ditolak, dengan demikian bahwa variabel Krisis Ekonomi (X2) berpengaruh signifikan terhadap PMDN.

Agar mengetahui hubungan atau pengaruh antara variabel independen secara bersama-sama terhadap variabel dependen, maka dilakukan Uji F Dengan kriteria pengujian Jika $\mathrm{F}$ hitung $<\mathrm{F}$ tabel, maka Ha ditolak dan Ho diterima, ini berarti variabel independen secara bersama-sama tidak mempengaruhi variabel dependen. (tidak signifikan). Jika $\mathrm{F}$ hitung > F tabel, maka $\mathrm{Ha}$ diterima dan Ho ditolak, ini berarti variabel independen secara bersamasama mempengaruhi variabel dependen (signifikan). Berdasarkan hasil analisis regresi diatas bahwa didapatkan nilai $\mathrm{F}$ hitung sebesar 8.972 dengan nilai signifikan sebesar 0.002. Nilai df ${ }_{1}$ sebesar 2, dan $\mathrm{df}_{2}=\mathrm{n}$ $-\mathrm{k}-1=21-2-1=18$ pada $\alpha=5 \%$ $(0,05)$ diperoleh nilai $F$ tabel sebesar 3.55 .

Nilai $\mathrm{F}_{\text {hitung }}>\mathrm{F}_{\text {tabel }}(8.972>$ 3.55). Maka dapat ditarik kesimpulan bahwa Ha diterima, Ho ditolak artinya variabel suku bunga kredit dan krisis ekonomi berpengaruh secara serentak atau bersama-sama terhadap PMDN dengan hasil yang signifikan.

Agar mengetahui kontribusi variabel bebas terhadap variabel terikat dapat dilihat dari Koefisien determinasi $\left(\mathrm{R}^{2}\right)$. Nilai $\mathrm{R}^{2}$ besarnya antara $0<\mathrm{R}^{2}<1$, dimana semakin mendekati 1 maka dapat diyatakan model semakin baik. Koefisien determinasi $\left(\mathrm{R}^{2}\right)$ sebesar 0.499 atau $49.9 \%$. Hal ini berarti kemampuan variabel bebas yang terdiri dari suku bunga kredit dan krisis ekonomi dalam menjelaskan variabel terikat (PMDN) sebesar 0.499 (49.9 \%), sedangkan sisanya $50.1 \%(1-0.499=$ $0.501)$ dijelaskan oleh variabel lain di 
luar model yang secara implisit tercermin pada variabel pengganggu.

\section{PENUTUP}

Perkembangan Penanaman

Modal dalam Negeri (PMDN) di Indonesia pada tahun 1990-2010 cenderung meningkat walaupun pada tahun tertentu juga mengalami penurunan. Hal ini terjadi dikarenakan di tahun 1990-2010 Indonesia mengalami 2 kali krisis ekonomi yaitu pada tahun 1998-2010 yang mengakibatkan penanaman modal dalam negeri menurun. Adapun perkembangan tingkat suku bunga kredit di Indonesia pada tahun 1990-2010 pergerakannya mengalami penurunan walaupun ditahun tertentu mengalami kenaikan dengan tingkat suku bunga kredit yang terbesar yaitu pada saat krisi ekonomi tahun 1998 mencapai $23.2 \%$ dan yang terendah pada tahun 2010 mencapai $12.28 \%$.

Suku Bunga Kredit $\left(\mathrm{X}_{1}\right)$ mempunyai pengaruh negatif terhadap PMDN sebesar -0.094 atau $9.4 \%$, yang artinya apabila Suku bunga kredit mengalami peningkatan maka Penanaman Modal Dalam Negeri akan mangalami penurunan. Dan sebaliknya apabila suku bunga mengalami penurunan maka Penanaman Modal Dalam Negeri akan mengalami peningkatan. Sedangkan krisis Ekonomi $\left(\mathrm{X}_{2}\right)$ mempunyai pengaruh positif terhadap Penanaman Modal Dalam Negeri sebesar 0,371 .

Berdasarkan hasil regresi tingkat suku bunga kredit mempunyai pengaruh yang signifikan terhadap penanaman modal dalam negeri. Hal ini ditunjukkan oleh uji $\mathrm{t}$ dimana $\mathrm{t}$ hitung (-4.235) > t tabel (2.101). Dan begitu juga dengan krisis ekonomi yang memiliki nilai $\mathrm{t}$ hitung sebesar 2.432 berarti krisis ekonomi juga mempunyai pengaruh terhadap penanaman modal dalam negeri.

\section{DAFTAR PUSTAKA}

Boediono. 1997. Seri Sinopsis, Ekonomi Makro. Edisi Keempat. Yogyakarta : BPFE.

Dumairy. 1996. Perekonomian Indonesia. Jakarta : Erlangga.

Hasan. Iqbal. 2004. Analisis Data Penelitian dengan Statistik. Jakarta : PT Bumi Askara.

Mangkoesoebroto, Guritno dan Algifari. 1998. Teori Ekonomi Makro. Edisi Ketiga. Yogyakarta : STIE YKPN. 
Mankiw, N. Gregory. 2000. Teori Makro Ekonomi. Edisi Keempat. Jakarta : Erlangga.

Nachrowi, Djalal Nachrowi dan Usman, Hardius. 2005. Penggunaan Teknik Ekonometri. Edisi Revisi. Jakarta : PT Raja Grafindo Persada.

Nasution, Mulia, S.E. 1998. Ekonomi Moneter, Uang dan Bank. Jakarta : Djambatan

Samuelson, Paul. A \& Nordhaus, William D. 1992. Makroekonomi. Edisi Keempatbelas. Jakarta : Erlangga.

Sukirno, Sadono. 2004. Teori Pengantar Makroekonomi.
Edisi Ketiga. Jakarta : PT Raja Grafindo Persada.

Wijaya M, Faried, Dr, M.A. 1997. Seri Pengantar Ekonomika, Ekonomika makro. Edisi Ketiga. Yogyakarta : BPFE.

www.bi.go.id. diakses 17 Februari 2011.

www.bkpm.go.id. diakses 17 Februari 2011.

www.bps.go.id. diakses 18 Februari 2011.

Yuliati, Uci. 2001. Pengantar Ekonomi Makro. Malang : Universitas Muhammadiyah Malang. 